\title{
Analysis of the Cause of Titanium Endoprosthesis Failure
}

Patrícia Hanusová, Peter Palček, Milan Uhríčik

Faculty of Mechanical Engineering, Žilinská univerzita. Univerzitná 8215/1, 01026 Žilina. Slovakia. E-mail: patricia.hanusova@fstroj.uniza.sk, peter.palček@fstroj.uniza.sk,milan.uhricik@fstroj.uniza.sk

This paper deals with the causes of failure of total hip replacement. Hip joint replacement is one of the most frequently used surgical procedures worldwide. More than 200,000 surgeries are performed only in Europe each year, following early attempts by John Charnley. Currently, more than 340 of the total 4431 implants per year are reoperated in Slovakia. Despite the excellent properties of the titanium alloy, endoprosthesis often fails and the hip replacement is necessary. Common causes are overloading and cracking, static or dynamic. Other causes of failure include injury, implantation failure, manufacturing inaccuracies, and non-compliance with the manufacturing process.

Keywords: endoprosthesis, fatigue, titanium alloy, hip joint

\section{Introduction}

Hip replacement is a surgical procedure in which parts of a hip joint are removed and replaced with a prosthesis, most commonly made of titanium-based alloys, especially Ti-6Al-4V. Although great advances have been made in this field, the fracture (Fig. 1) is still one of the main problems associated with hip implant failure. [1 ]Double-modular hip implants consist of a neck that is separate from both the stem and the head - the three parts fit together via tapered joints. Several necks and heads of different geometries are available, allowing the surgeon to optimize the hip angle, hip offset, and leg length during surgery. However, concerns exist about the stability of the tapered joints used to connect the neck to the head and stem. Specifically, tapered joints are susceptible to corrosion, which may lead to the release of toxic metal ions and mechanical failure. [2]

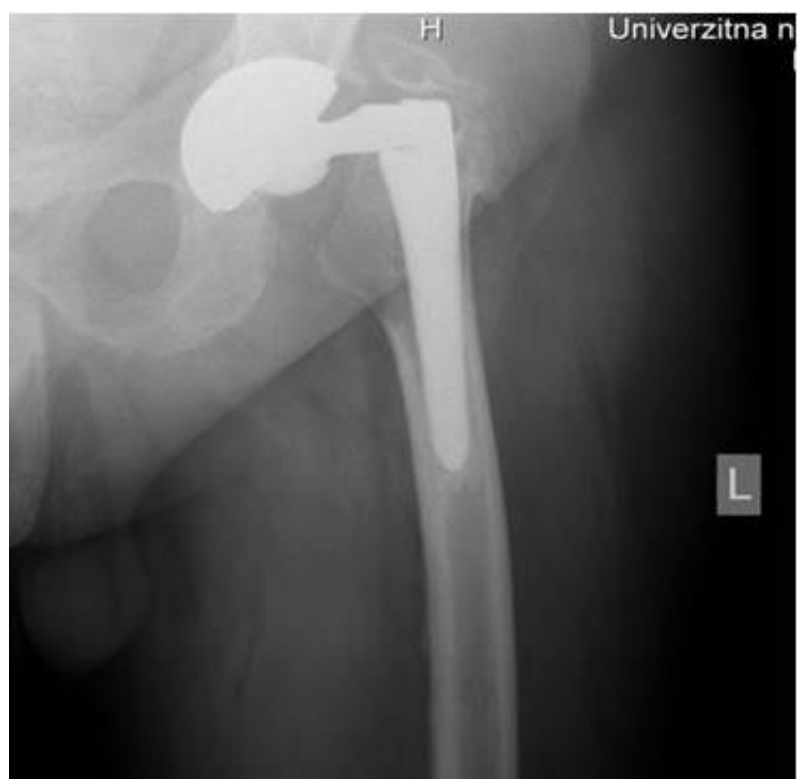

Fig. 1 Failure of hip endoprosthesis on X-ray

Forces and moments are transferred from the upper body to the leg across the hip joint loading the femoral neck in bending. In bi-modular hip systems, the taper connection between stem and neck adapter is situated in the part of the neck, where high moments act as a result of the large lever arm between joint friction and the force vector of the joint force. [5]Each prosthesis component is subjected to a different set of loads that is specific to the individual patient. Also, the anchoring conditions vary depending on the patient's pre-existing diseases, design of the prosthesis, quality of bone and surgical implantation techniques. One should also keep in mind that scratches inevitably appear on the implant surface, causing stress concentration, and providing a location for crack initiation and propagation. [1]

\section{Materials and methods}

Standards have been developed to test the fatigue properties of femoral stems; however, the loads that these apply are based on a historic patient's weight and may not be valid in the current patient population. Several fatigue tests were conducted using fixed titanium alloy stems fixed according to ISO standard but with cyclic load based on current 75 th percentile patient sample. [3]

The implant recipient was described as 61 year-old male, weighing $84 \mathrm{~kg}$ with BMI index 27,8 , which is considered as overweight. The implant consisted of a size 3 of femur stem. Both the neck and stem were made of Ti6Al4V, and the head was made of a ceramic polymer. The neck of this implant failed after eleven years (implanted in 2008, failed and removed in 2019). The operation was performed at Orthopaedic clinic of University hospital and Jessenius faculty of medicine of Comenius University in Martin, Slovakia.

The fractured endoprosthesis was surgically extracted from the patient's left leg. Experiments were implemented to clarify the causes of the fracture. Microstructures of both parts and neck were examined by endoprosthesis using a NEOPHOT 32 light microscope. The samples were metallographically prepared with TEGRAPOL 15 and etched with $10 \% \mathrm{HF}$. Furthermore, Surface of fracture was observed on TESCAN VEGA LMU2emission scanning electron microscope (SEM). The examined samples were made from titanium alloy Ti6Al4V, which was confirmed by spectral analysis (Fig. 2). Microhardness was measured using a ZWICK ROELL with a load of $0.5 \mathrm{HV}$. 


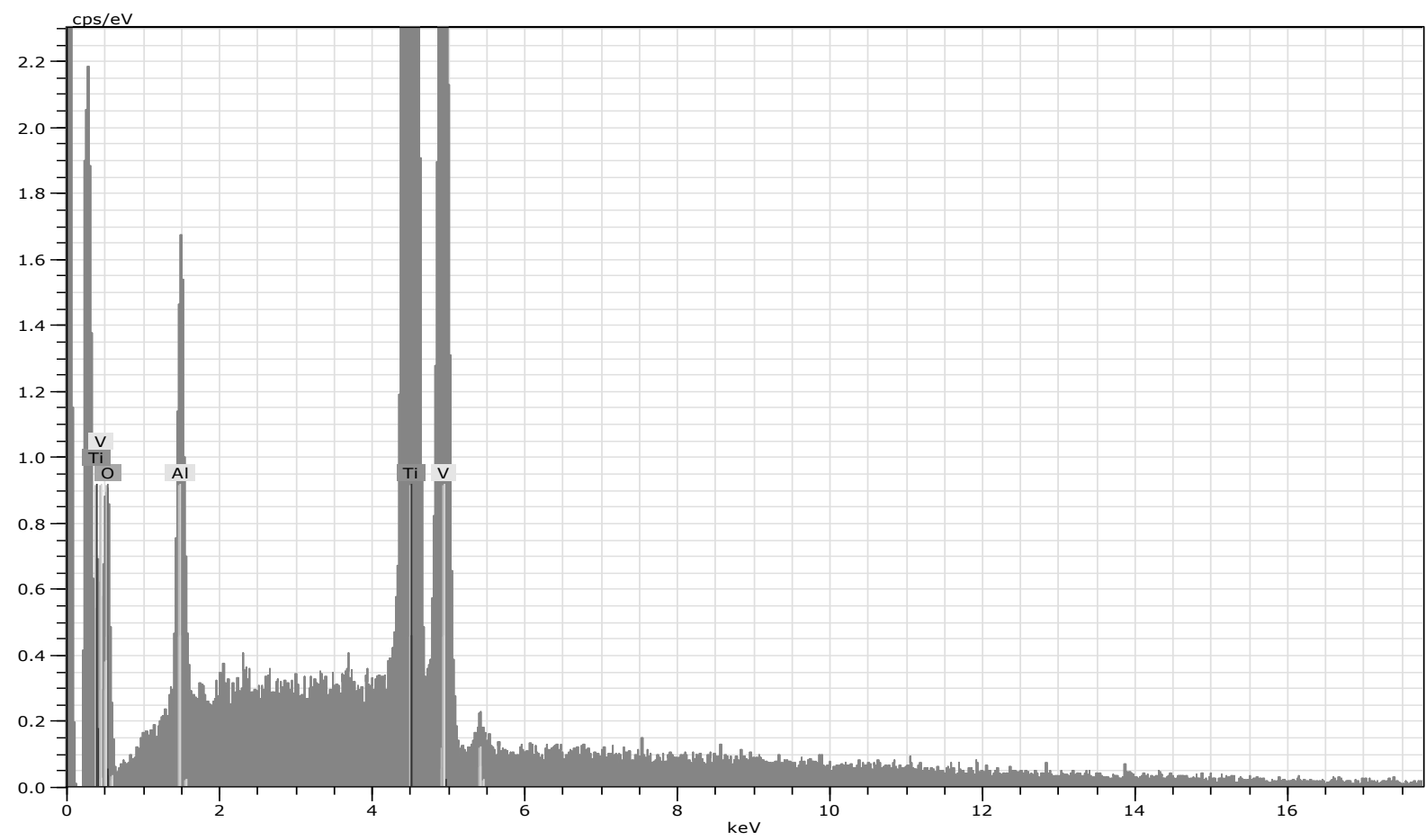

Fig. 2 Spectral analysis of endoprosthesis

\section{Results and discussion}

\subsection{Microstructure}

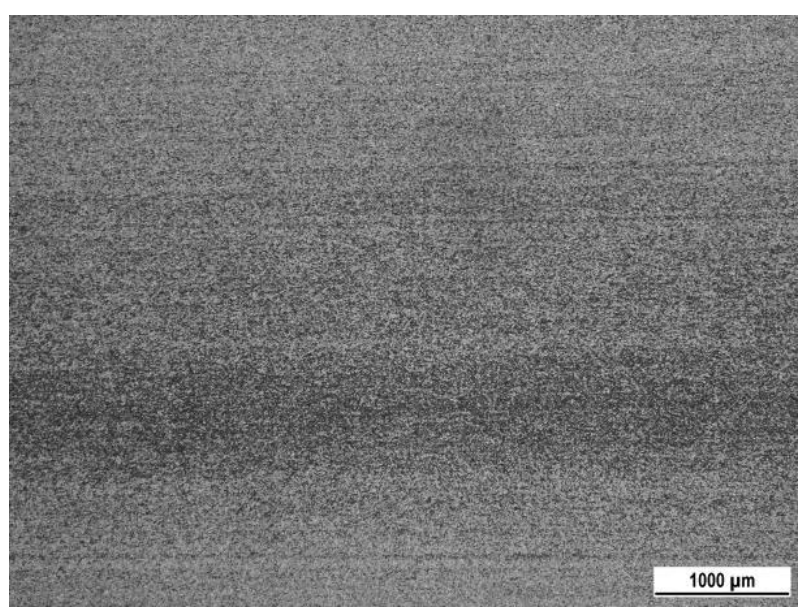

a) $25 x$ magnification, etched $10 \% \mathrm{HF}$

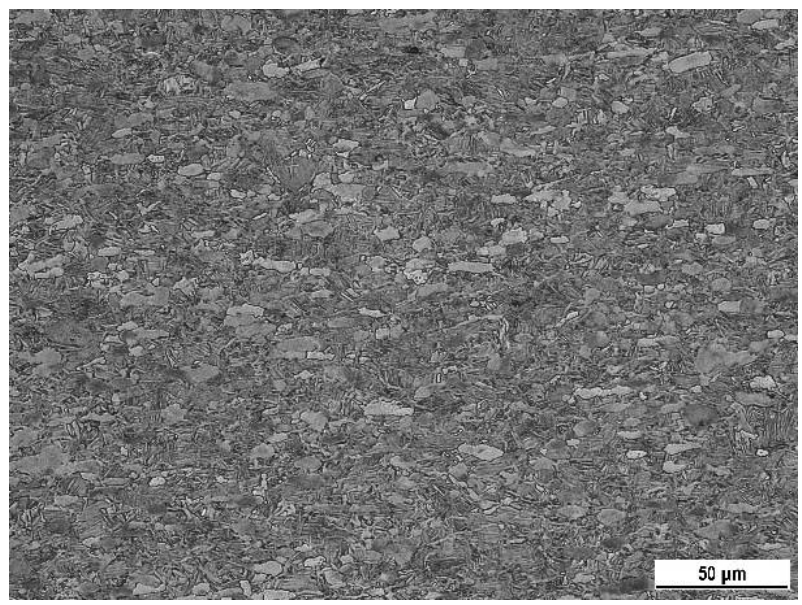

b) 500x magnification, etched $10 \% \mathrm{HF}$

Fig. 3 Microstructure of stem
The study of microstructure confirmed the divergence changes in the items of implant. The neck part of the prosthesis (Fig. 3) was made by casting. The microstructure of the sample is very fine-grained. The stem part (Fig. 4) was forged to the desired shape. The different microstructures are caused by different methods of manufacturing.

Titanium exists in two allotropic forms. At low temperatures, it has a close-packed hexagonal crystal structure, which is known as $\alpha$. Whereas above $882{ }^{\circ} \mathrm{C}$ it has a body-centered cubic structure known as $\beta$. From $\alpha-$ to $\beta$ - transformation temperature of pure titanium either increases or decreases based on the nature of the alloying elements, either alpha stabilizers (Al, O, N, etc.) or beta stabilizers (V, Mo, Nb, Fe, Cr, etc.). The existence of $\alpha$ or $\beta$ transformation means that a variety of microstructures and property combinations can be achieved in the alloy through thermomechanical processing. [3]

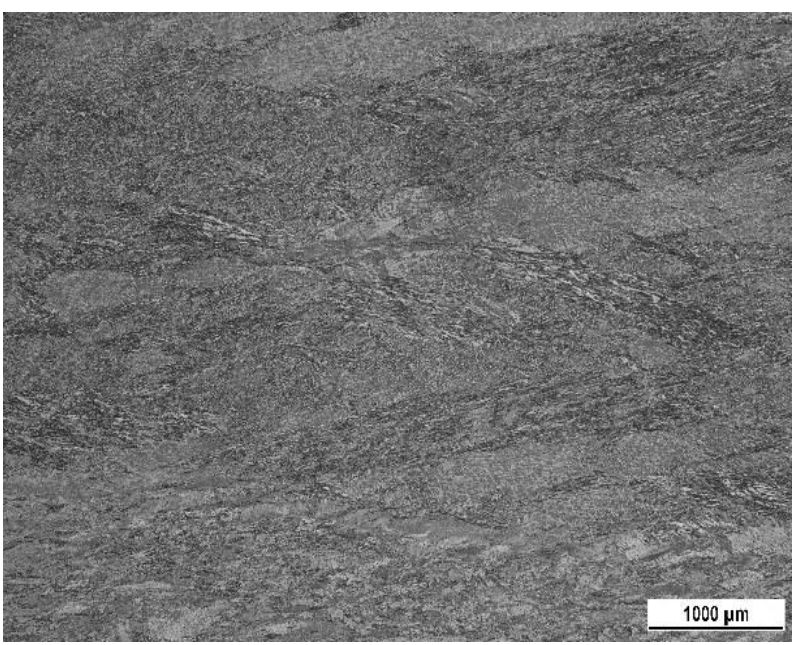

a) $25 x$ magnification, etched $10 \% \mathrm{HF}$ 


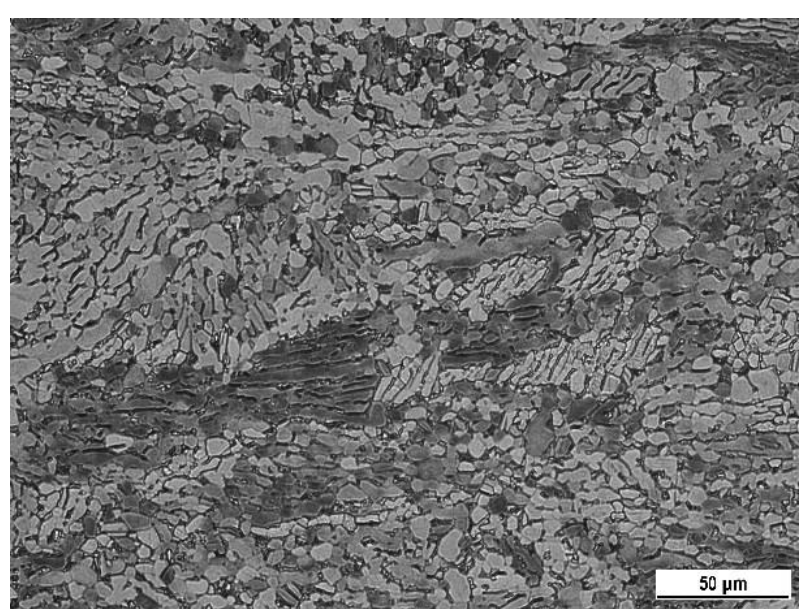

b) 500x magnification, etched $10 \% \mathrm{HF}$

Fig. 4 Microstructure of neck

\subsection{Microhardness}

By measuring the hardness of the neck of endoprosthesis specimen, 49 points were determined in a horizontal direction with a $250 \mu \mathrm{m}$ spacing of the individual indentations. The hardness values of this specimen ranged from $201 \mathrm{HV}$ to $353 \mathrm{HV}$. The average microhardness value was $309.47 \mathrm{HV}$ 0.5. The measurement was linear along with the whole sample.

To measure the hardness of the stem of endoprosthesis determination of 30 points in the horizontal direction. The interval at which the hardness values were varied was 243 $\mathrm{HV}$ to $341 \mathrm{HV}$. The calculated average hardness of the endoprosthesis stem sample was $301.9 \mathrm{HV}$.

Comparaison the average hardness values of the individual specimensa aproved that the neck sample of the endoprosthesis has slightly higher hardness values than that of the endoprosthesis stem.

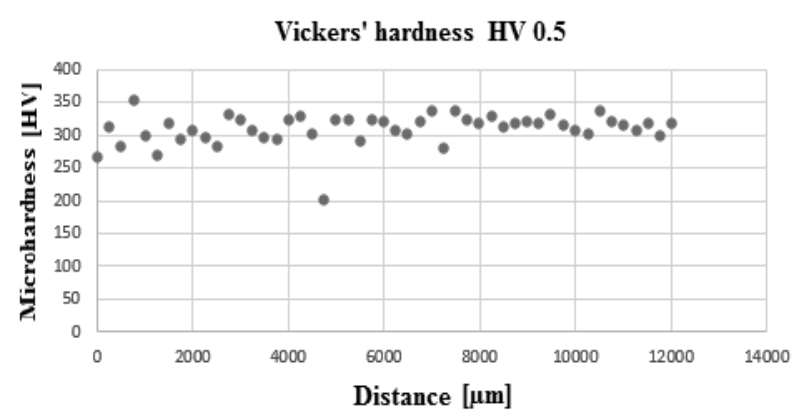

a) neck

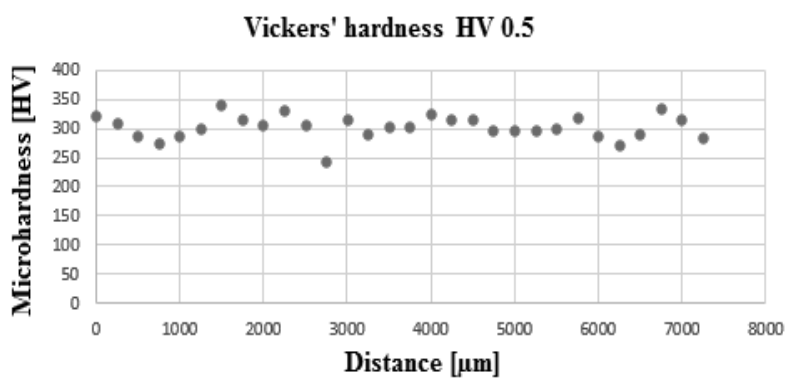

b) stem

Fig. 8 Vickers' microhardness HV 0.5

\subsection{Fractography of fracture surface}

The overall view of the neck of the endoprosthesis is considered to be fatigue ( $F$ ig. $5 \mathrm{a}$ ). The area is divided into fatigue portion and a part to failed statically. The border has a width and it is not possible to precisely determine the boundary line. Fatigue started at the place with the highest stress concentration - initiation of fatigue crack (Fig. 5b).

Study of material properties by SEM confirmed dendritic structure (Fig. 6a) detectable also on the optical microscope. When analyzing the fatigue area of the neck of the endoprosthesis, transcrystalline ductile failure with fatigue lines-striations (Fig. 6b) were investigated. It is confirming the occurrence of fatigue material during stress.

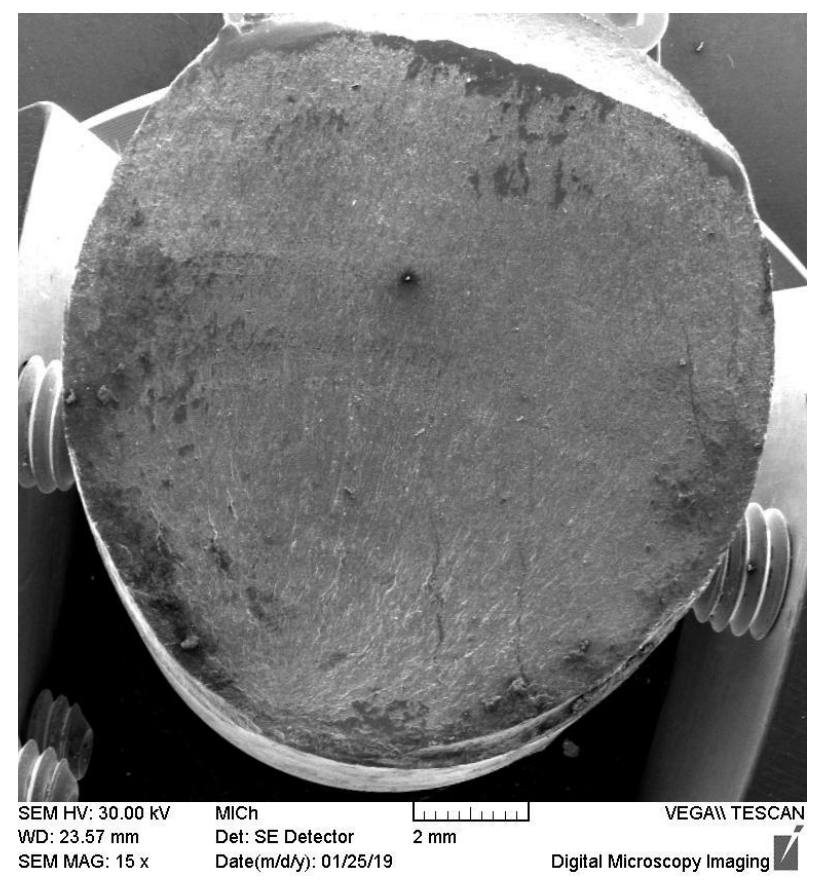

a) general view

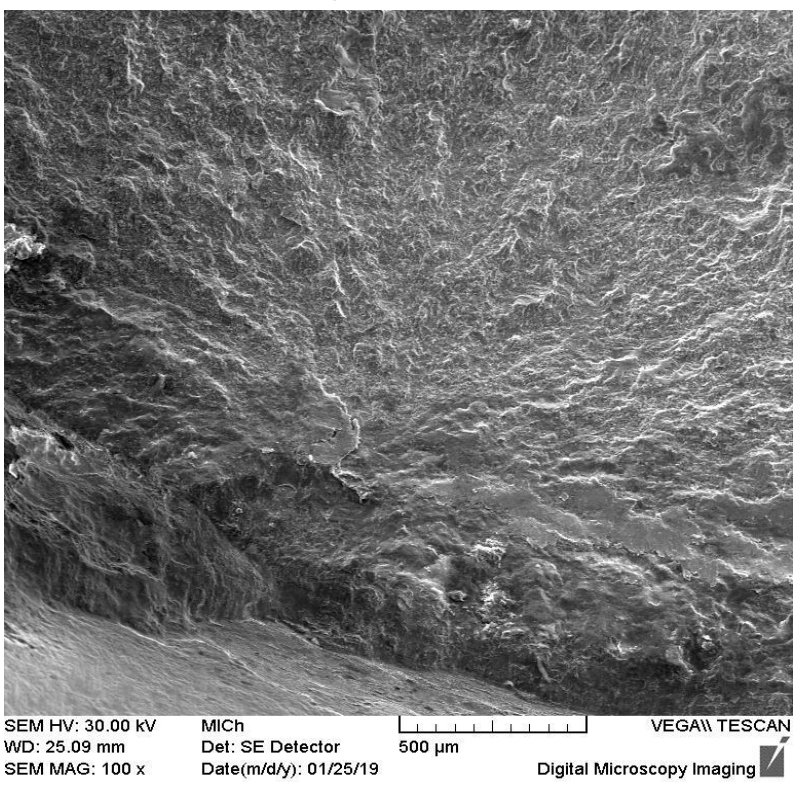

b) the place of inicialization of fatigue

Fig. 5 Surface of the fracture 
Secondary cracks were confirmed on the fracture surface. Their orientation is influenced by the linearity of the structure. Existing oxide layer fragments demonstrated the presence of corrosion. At the bottom, chlorides and oxides of titanium were proved by the BSE method.

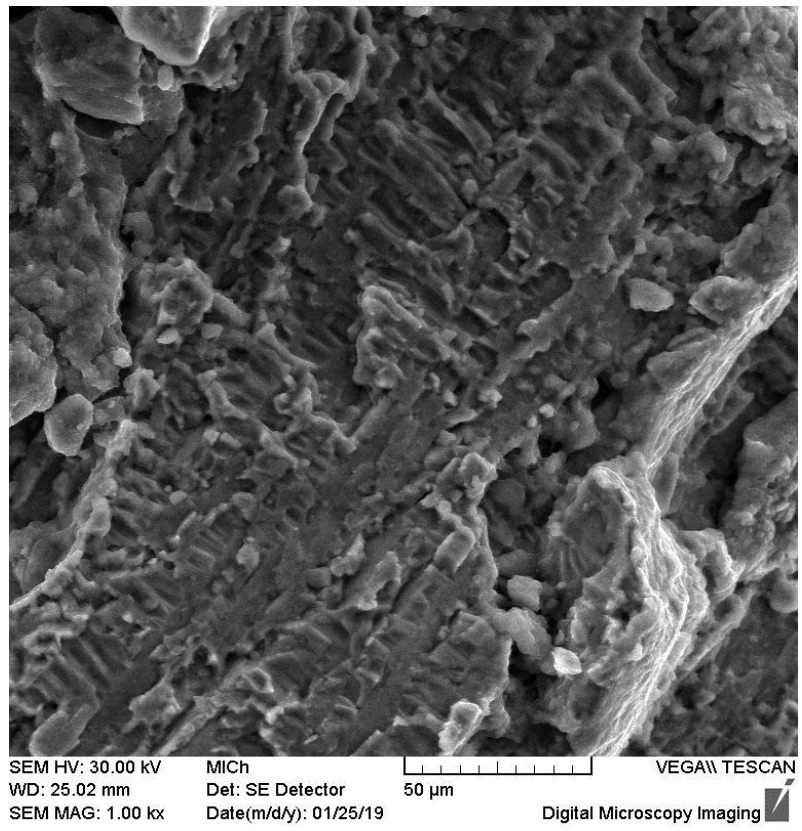

a) dendrit structure od neck

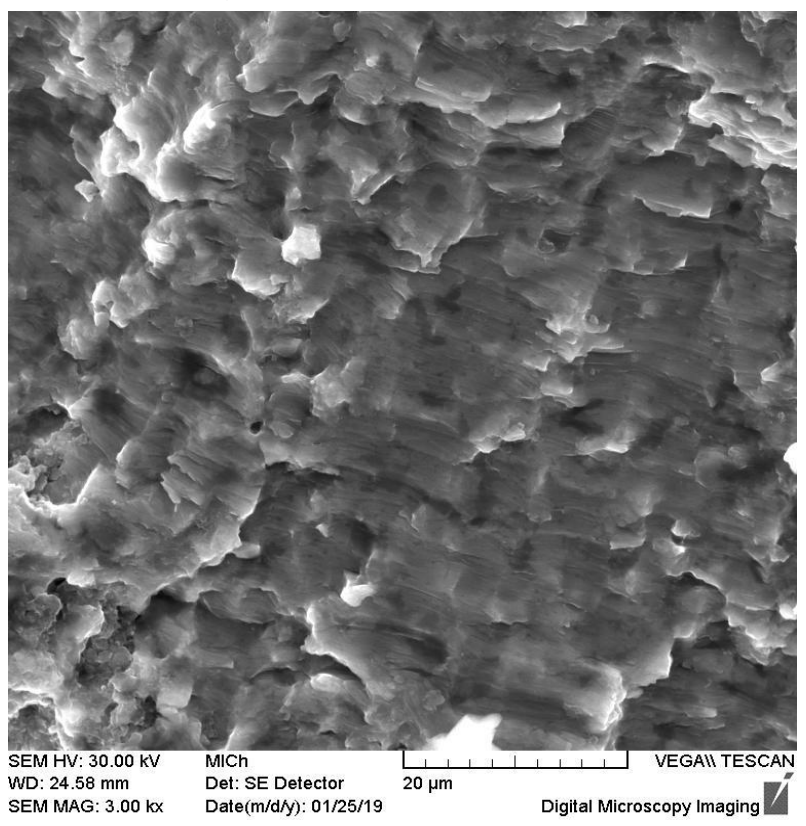

b) striations

Fig. 6 Fractography of fracture surface

\section{Conclusion}

The results suggest that while fatigue properties of medical-grade titanium are very good, the ISO pre-clinical dura-bility testing standard does not represent the influence of femoral offset or stem. Size sufficiently to reflect safe design practice. This research demonstrates that the main causes of prosthesis failure are manufacturing inaccuracies and micromotions at the stem-neck interface. At these points, stress is concentrated and a fatigue crack is created, which leading to material failure. The largest micromotions were observed at the lateral edge of the stem-neck taper connection, which is in accor-dance with the crack location. In the case of normal walking, the lifespan of the damaged implant is long, but at higher loads (running, climbing up the stairs) the lifespan of an implant is significantly shorter.

\section{Acknowledgement}

This work was supported under the project of Operational Program Research and Innovation: Research and development activities of the University of Zilina in the Industry of 21st century in the field of materials and nanotechnologies, No. 313011T426. The project is co-funding by European Regional Development Fund.

This research was also supported by Project KEGA $n^{\circ} 013 \check{Z} U-4 / 2019$.

\section{References}

[1] ČOLIĆ, K. et al. (2017) Experimental and numerical research of mechanical behaviour of titanium alloy hip implant. In: Tehnički vjesnik-Technical Gazette, Vol. 24, No. 3, pp. 709-713.

[2] WILliAMS, Jason J.; CHAWLA, Nikhilesh. (2014) Fractography of a neck failure in a doublemodular hip implant. In: Case Studies in Engineering Failure Analysis, Vol. 2, No. 1, pp. 45-50.

[3] WESTERMAN, Ashley P., et al. (2018) Hip stem fatigue: The implications of increasing patient mass. In: Proceedings of the Institution of Mechanical Engineers, Part H: Journal of Engineering in Medicine, Vol. 232, No.5, pp. 520-530.

[4] JENKO, Monika, et al. (2018) Surface chemistry and microstructure of metallic biomaterials for hip and knee endoprostheses. In: Applied Surface Science, Vol. 427, pp.584-593.

[5] JAUCH, S. Y., et al. (2014) Design parameters and the material coupling are decisive for the micromotion magnitude at the stem-neck interface of bi-modular hip implants. In: Medical engineering \& physics, Vol. 36, No.3, pp. 300-307.

[6] JAUCH, S. Y., et al. (2011) Influence of material coupling and assembly condition on the magnitude of micromotion at the stem-neck interface of a modular hip endoprosthesis. In: Journal of biomechanics, Vol. 44, No.9, pp. 1747-1751.

[7] SEDMAK, A., et al. (2019) Numerical analysis of fatigue crack growth of hip implant. In: Engineering Fracture Mechanics, Vol.216, Article 106556 